\title{
Effect Of Casein Phospopeptide-Amorphous Calcium Phospate Application On Saliva Acidity Levels In Children Aged 10 - 12 Years
}

\author{
Yufitri Mayasari ${ }^{1}$ and Asya Sherina Khansa ${ }^{2}$ \\ \{yufitrimayasari@dsn.moestopo.ac.id ${ }^{1}$, asyakhansa@yahoo.com² ${ }^{2}$ \\ ${ }^{1}$ Department of Dental Public Health, Faculty of Dentistry, Universitas Prof Dr Moestopo \\ (Beragama), Jakarta, 12320, Indonesia \\ ${ }^{2}$ Clinical Programme, Faculty of Dentistry, Universitas Prof Dr Moestopo (Beragama), Jakarta, \\ 12320, Indonesia
}

\begin{abstract}
Dental caries was one of the prevalent disease worldwide. There was four main factors that cause dental caries, namely the host factor, agent, environment, and diet. As the environment factor was saliva. The saliva acidity levels $(\mathrm{pH})$ were very influential on the occurrence of dental caries. One of preventive material was Casein phosphopeptide-amorphous calcium phosphate (CPP-ACP). This study was an experimental clinical study that aims to determine the impact of a treatment on research subjects. The design used in this study was pretest-posttest design.. The participants were 30 children that obtained with purposive sampling. The saliva of the children were collected before and after topical application CPP-ACP. The salivary acidity level was using dental saliva $\mathrm{pH}$ indicator. The mean of saliva acidity level before CPP-ACP application is 7.6333 and after CPP-ACP topical application becomes 7.7467. The saliva acidity levels difference test obtained $\mathrm{p}$-value $=0.000(\mathrm{p}<0.5)$ means that there is a significant difference in $\mathrm{pH}$ level between before and after CPP-ACP topical application. This conclusion conclude that there was an increase in the level of salivary acidity before and after topical application of CPP-ACP.
\end{abstract}

Keywords: saliva, cpp-acp, acidity, children

\section{Introduction}

Dental caries is one of the most chronic diseases that occur in children. A number of epidemiological studies have found dental caries as a major public health problem worldwide[1]. A recent study reported that caries prevalence in Iranian children aged $6-9$ years is $80-90 \%$ with average DMFT values ranging from 3.3 to 4.8.[2] Dental caries can affect the quality of life of children. Evident from several studies found that children under the age of 2 years, dental caries could cause weight loss and inhibit growth.[1] In general, there are four main factors that cause dental caries, namely the host factor, agent, environment, and diet. As for the environment factor is the condition of saliva.

The conditions of saliva in question are related to the level of production, flow, viscosity, and acidity level or commonly called salivary $\mathrm{pH}$. The level of $\mathrm{pH}$ from the environment around the mouth is very influential on the occurrence of dental caries. Under normal conditions, the remineralization and demineralization process will occur continuously in the oral cavity. 
The imbalance between protective factors and pathological factors can cause the release of Calcium and Phosphate ions, which marks the start of the demineralization process[4]. Although agent, diet and host factors also have an important role in the process of dental caries, environmental factors, namely salivary $\mathrm{pH}$, are the determinants of the process demineralization $[3,5]$. In the development of the field of material science Dentistry, various preventive materials have been found that can be used to prevent dental caries, one of which is Casein phosphopeptide-amorphous calcium phosphate (CPP-ACP). CPP-ACP is a unique natural protein-based remineralization technology and is used globally in the form of chewing gum (such as Recaldent ${ }^{\mathrm{TM}}$ ) and topical cream (such as GC Tooth Mousse ${ }^{\mathrm{TM}}$ and Tooth Mousse Plus $\left.^{\mathrm{TM}}\right){ }^{2}$ The content of calcium and phosphate in this material can stabilize the cavity acidity mouth and maintain the remineralization process.[2] Based on the explanation above, researchers want to try to examine the effect of Casein Phosphopeptide Amorphous Calcium Phosphate (CPP-ACP) topical application on salivary acidity in children aged 10-12 years in Strada Bakti Utama Elementary School, South Jakarta.

\section{Method}

The type of research used in this study was experimental clinical. This type of experimental research was one of the quantitative research procedures that aims to determine the impact of a treatment on research subjects. The research design used in this study was pretest-posttest design. The design of this study was done by pretest in advance to find out the initial state of the research subjects after which the treatment was given followed by giving a posttest to find out the differences. In this study 2 variables are used, namely an independent variable (independent variable) and a dependent variable. In this study which is the independent variable is the CPP-ACP application and the dependent variable is the level of saliva acidity in 30 children aged 10-12 years in Strada Bakti Utama Elementary School.

The study population was all students aged 10-12 years at Strada Bakti Utama Elementary School. The inclusion criteria in this study were students whose parents signed informed consent as proof of the agreement to participate in this study, students with 0 or 1 dental caries, students who did not have cow's milk allergy, and students who did not take drugs. The exclusion criteria in this study were students whose parents had signed the informed consent but were not present or did not follow this research until it was completed. The flow of this study was first the students were asked to accommodate saliva in a plastic container as much as $1 \mathrm{ml}$, then measured salivary acidity level was using dental saliva $\mathrm{pH}$ indicator and students were asked to wash their hands, then students were given CPP-ACP topical application as much as $1 \mathrm{mg}$ and flattened using tongue to the entire surface of the tooth, after 15 minutes, students were asked to return to accommodate $1 \mathrm{ml}$ of saliva, then measured the $\mathrm{pH}$ of the saliva again. This research has been approved by FKG Ethics Committee of Prof. Dr. Moestopo University (B) with letter No. 070/loloskajietik/FKGUPDM (B)/VI/2018.

This research was conducted as a part of a qualitative study conducted at the Fish Auction (TPI) at Gauang Market, Padang, in 2015. The data collection process was conducted through in-depth interviews with agents or fish distributors, wholesalers, intermediate traders, small traders, and management of Koperasi Minagates and the members. The observation process was conducted to observe and catch the real market activity in TPI Gauang. Various activities were noted and recorded with a camera. The document studies were carried out to complement the secondary data related to the completion of this research. The documents studied in this study are the research reports, journal articles, and literature that support the writing of this 
research. The data analysis was performed by systematic testing of the data, categorizing the data, and finding the relationships between categories [17].

\section{Result}

This study aims to determine the effect of Casein Phosphopeptide-Amorphous Calcium Phosphate application on salivary acidity in children aged 10-12 years at Strada Bakti Utama Elementary School. The results of the study can be seen in the following table:

Table 1. Distribution of samples by sex $(n=30)$

\begin{tabular}{ccc}
\hline Gender & $\mathrm{n}$ & $\%$ \\
\hline Male & 16 & 53,3 \\
Female & 14 & 46,7 \\
\hline
\end{tabular}

Table 1 shows that based on the sex distribution of male samples as many as $16(53.3 \%)$, while the female sample was $14(46.7 \%)$.

Table 2. Distribution of samples based on age $(n=30)$

\begin{tabular}{ccc}
\hline Age & $\mathrm{N}$ & $\%$ \\
\hline 10 Years old & 3 & 10 \\
11 Years old & 25 & 83.3 \\
12 Years old & 2 & 6.7 \\
\hline
\end{tabular}

In table 2 shows that the distribution of research samples based on age, age 10 years as many as $3(10 \%)$, age 11 years as many as 25 people $(83.3 \%)$, age 12 years as many as 2 $(6.7 \%)$.

Table 3. Average Comparison of Saliva Acidity Levels Before and After CPP -

\begin{tabular}{ccc} 
& ACP Applications & \\
\hline & Mean & SD \\
\hline pH before & 7,6333 & 0,17486 \\
pH after & 7,7467 & 0,10417 \\
\hline
\end{tabular}

In table 3 shows a comparison of the average increase in saliva acidity level before CPPACP application is 7.6333 and after CPP-ACP topical application becomes 7.7467 . From the results of the normality test (Shapiro-wilk test), the results showed that the variables of saliva acidity level before and after CPP-ACP application had $\mathrm{p} \leq 0.05(\mathrm{p}=0.000)$. Means that the data is not normally distributed.

Table 4. Test of Differences in Saliva Acidity Levels Before and After CPP- ACP Applications

\begin{tabular}{lccc}
\hline & $\mathbf{n}$ & $\begin{array}{c}\text { Median } \\
(\text { minimum-maximum) }\end{array}$ & \multicolumn{1}{l}{$\mathbf{p}$} \\
\hline Before & 30 & $7.6(7.2-7.8)$ & $0.000^{*}$ \\
After & 30 & $7.8(7.4-7.8)$ & \\
\hline
\end{tabular}


In table 4 , from the saliva acidity difference test obtained $p$-value $=0.000(p<0.5)$ means that there is a significant difference in $\mathrm{pH}$ level between before and after CPP-ACP topical application.

\section{Discussion}

CPP-ACP or casein phosphopeptide amotphous calcium phosphate is a technology that is found with the ability to remineralize and has been used globally in dental practice and was made in the form of gum and paste.[6] Measurements were made by measuring the saliva acidity of children aged 10-12 years at Strada Bakti Utama Elementary School before and after topical application of CPP-ACP using a Dental pH Saliva Indicator. Dental pH Saliva Indicator provides a measurement of values based on color, namely red (pH 5.0 - 5.8), yellow $(\mathrm{pH} 6.0$ - 6.6), and green ( $\mathrm{pH} 6.8$ - 7.8). In this study, two measurements were taken for salivary acidity before topical application of CPP-ACP and salivary acidity after CPP-ACP topical application.

Based on table 1 the distribution of samples based on sex with a total sample of 30 people consisting of male as many as $16(53.3 \%)$ and female as many as $14(46.7 \%)$.

Based on table 2 the study sample based on age, age 11 years is the largest sample with a total of 25 people $(83.3 \%)$, ten years old as many as $3(10 \%)$, then with the smallest sample age 12 years as many as $2(6.7 \%)$. From the data that has been obtained, significant results were obtained for measuring the level of salivary acidity before and after topical application of CPP-ACP. Based on the data from Table 3, the average value of saliva acidity before CPPACP application was 7.6333 and there was an increase in saliva acidity after CPP-ACP topical application with an average of 7.7467. The results showed an increase in salivary alkalinity after topical application of CPP-ACP. The same method research showed that from 43 control groups, the average saliva acidity ranged from 7,174 before brushing teeth and saliva acidity level increased to 7,593 after brushing using fluoride.[7,8,9] The average change in saliva acidity level before and after brushing teeth contained fluoride of 0.216 . A study on children aged 6-12 years with a total subject of 40 people, showing the average level of saliva acidity after using mouthwash and toothbrush in a period of 30 minutes and 60 minutes after brushing your teeth and gargling using mouthwash. The average salivary acidity level was 7.8 after gargling with mouthwash, and the average salivary acidity level was 7.78 after brushing teeth within 30 minutes after treatment. Average saliva acidity level was 7.83 after gargling with mouthwash, and the average saliva acidity level was 7.85 after brushing teeth, both obtained in a span of 60 minutes after treatment.

The more frequent of the application of CPP-ACP the salivary calcium, phosphate, and $\mathrm{pH}$ levels will increase. Salivary $\mathrm{pH}$ is measured with a Dental saliva $\mathrm{pH}$ indicator. The results showed salivary $\mathrm{pH}$ before the lowest CPP-ACP topical application $(6.1091 \pm .10193)$. The highest salivary $\mathrm{pH}$ after 28 times of application $(7.7273 \pm .14535)$. CPP-ACP works well and efficiently mineralizes agents in $\mathrm{pH}$ acidity, and is neutral and in an alkaline phosphate range. $[10,11,12]$ Thus it can be seen in this study that CPP-ACP affects the acidity level of child saliva.

\section{Conclusion}

Based on the results of the study regarding the effect of Casein Phospopeptide-Amorphous Calcium Phosphate application on saliva acidity levels in children aged 10-12 years in SD Strada Bakti Utama, the following conclusions are: 
1. There is a change in the level of salivary acidity before and after topical application of CPP-ACP.

2. The results showed that there was an increase in the level of salivary acidity before and after topical application of CPP-ACP.

\section{References}

[1] Poureslami H, Hoseinifar Ra, Hoseinifar Re, Sharifi H, Poureslami P,Concentration of Calcium, Phosphate and Flouride Ions in Microbial Plaque and Saliva after Using CPP - ACP Paste in 6 - 9 year-old Children, J Dent Biomater, 3(2): 214-219, 2016.

[2] Truin GJ, van Rijkom HM, Mulder J, Van't Hof MA. Caries Trends 1996-2002 Among 6- and 12-year-old Children and Erosive Wear Prevalence Among 12-YearOld Children in The Hague. Caries Res. ,39:2-8, 2005.

[3] Ozdemir D. Dental Caries an Preventive Strategies. $J$ of Edu and Instructional Studies in The World. ,Nov, 4 (4), 2004.

[4] Athena S. Papas, Mabi L. Singh. Remineralization Strategies : Dental Caries' Slow Progression Offers Dental Professionals An Opportunity For Early Intervention. Inside Dentistry, Feb ; 6 (2), 2010.

[5] Darwita RR, Andreas P. Salivary Parameters of Buffer Capacity, pH Saliva and $\mathrm{pH}$ Plaque Related to Dental Caries Activity in School Student. J Clinical Preventive Dent, Nov; 9, 2013.

[6] Walsh LJ. Topical CPP - ACP cremes : beyond caries prevention. International Dent, 4(5), 2012. Available from URL: https://pdfs.semanticscholar.org/084c/21a36dbc4a6880f7ad308f43474c7707a49b.pdf

[7] Cross KJ, huq NL, Reynolds EC. Casein Phosphopeptide in Oral Health - Chemistry and Clinical Application. Current Pharmaceutical Design, 13(8), 2007.

[8] FitzGerald R. J., Potential Uses of Caseinophos-phopeptides., International Dairy Journal, 451-457, 1998.

[9] Gurunathan D, Somasundaram S, Kumar SA. Casein Phosphopeptide $\square$ Amorphous Calcium Phosphate: a Remineralizing Agent of Enamel. Australian dental journal, 57(4):404-8, 2012

[10] Matthews F. e Use of Sugar Free Chewing Gum as a Supplement In The Prevention of Dental Caries. Narrative Review. J Oral Res, 4(2): 129-136, 2015.

[11] Li J, Xie X, Wang Y, Yin W, Antoun JS, Farella M, et al. Long-term Remineralizing Effect of Casein Phosphopeptide-amorphous Calcium Phosphate (CPP-ACP) on Early Caries Lesions in Vivo: A Systematic Review. J Dent, 42, 769-77, 2014.

[12] S. MI Paste Plus Effect to Prevent White Spot Lesions Associated with Orthodontic Treatment. J Minim Interv Dent, 9: 1-3, 2016. 